Research Article

\title{
Implementing Fuzzy TOPSIS on Project Risk Variable Ranking
}

\author{
Saiful Husin (D), Fachrurrazi Fachrurrazi, Maimun Rizalihadi, and Mubarak Mubarak
}

Civil Engineering Department, Universitas Syiah Kuala, Banda Aceh, 23111 Aceh, Indonesia

Correspondence should be addressed to Saiful Husin; saifulhusin@unsyiah.ac.id

Received 6 April 2019; Accepted 19 June 2019; Published 8 July 2019

Academic Editor: Tayfun Dede

Copyright (c) 2019 Saiful Husin et al. This is an open access article distributed under the Creative Commons Attribution License, which permits unrestricted use, distribution, and reproduction in any medium, provided the original work is properly cited.

Managing construction risks with a large number of risks with small impact can increase the additional effort and cost of inefficient construction. Therefore the variables need to be eliminated. The aim of this study is ranking the risk variable based on its frequency of occurrence by integrating time, cost, and quality criteria simultaneously and selecting the top ten variables with the order of the most significant impact. The risk variable ranking based on triple project objective of cost, time, and quality simultaneously is a challenge for particular projects or regions contributing to the risk context. A number of 127 qualitative risk variables of 14 factors occurring in a project to be eliminated require a method/technique. A fuzzy TOPSIS method involving linguistics data is proposed to capture vague conditions. Results show that the top ten rankings of risk variables based on integrating the different weights of cost, time, and quality are successfully identified by concluding that the labour factor is the most dominant variable affecting project risk in context the rehabilitation and reconstruction posttsunami disaster, especially in Aceh-Indonesia. The variables are lack of labour, unskilled labour, undisciplined labour, and low productivity of labour. This condition can differ from different risk contexts. This research is different from other studies that only review cost, time, and quality separately. We stated that to integrate all three criteria of cost, time, and quality simultaneously is more logic to analyze risk variable ranking.

\section{Introduction}

In last year's, the development of risk analysis studies is increasing rapidly; this is due to proper risk assessment could decrease the failure rate to achieve the outcomes and objectives of budget, time, and quality for a project [1], especially in project involving massive resources, such as rehabilitation and reconstruction posttsunami disaster in Aceh-Indonesia [2]. Although new techniques and methods are introduced to various processes, such as software and automated tools [3], risk assessment for projects remains an unstructured problem that depends on human expertise $[4,5]$. In the risk analysis concept, identifying and assessing risk variables is an important step that should be conducted by a project manager to get an early warning about the possible risk variable using statistics [4] that can occur in the project. In a construction project, the risk variable is a source of risk that can arise due to internal project factors, such as labour, company finance, and equipment, and external factors, such as political situations, inflation, and market competition [6]. Aceh-Indonesia ever experienced largescale tsunami that caused severe infrastructure damage, and this event encouraged the world practitioners to rebuild Aceh through a rehabilitation and reconstruction program [7]. The very high reconstruction intensity in the period can be used as a lesson learned for contractors to recognise the more complex project risks that may also occur in other areas. Expansion of the size and complexity of a construction project would lead to an increase in the number of associated risk events rapidly [8].

Some previous studies have analysed the risk variable rank [9] using the index methods for either frequency [10], severity, or risk importance that it is contributing to the project objectives achievement. The research was not integrated simultaneously to achieve the project objective. Analysing risk variables are based on the three criteria of cost, time, and quality that can provide more relevant results than that compared to analytical methods based on separate criteria. The problem solving of risk variable ranking is using multicriteria with multiobjective, where each alternative of 
risk variable is a random variable or linguistic variable that should be applied in the risk problem. The problem is a challenge to be further analysed by considering the variable interaction between one to another variable of risk to achieve the three project objectives, namely, quality, time, and cost. Based on this condition, the aim of this study is ranking the risk variable based on its frequency of occurrence by integrating time, cost, and quality criteria simultaneously and selecting the top ten variables with the order of the most significant impact. A technique that makes it possible to realise these expectations is applying fuzzy logic as an algorithm to capture the disguises of perceptible perceptions combined with the Topsis method. This study proposes 127 risk variables categorised into 14 factors, and they are used to assess risk frequency in Aceh-Indonesia region based on three project objectives simultaneously. The frequency of risk variables is judged by 15 respondents that they are from the large contractors firm. The risk variable frequency could differ from one to another contractor depending on their experience in conducting project during the rehabilitation/ reconstruction of the posttsunami period in the region.

The risk variable is measured for its risk frequency of occurrence in a qualitative scale of very low, low, medium, high, and very high. Meanwhile, the importance of criteria weights for cost, time, and quality are measured based on the qualitative scale increasing very unimportant, less important, rather important, important, and very important. To support this research paper, we introduce some methods of project risk that have been published and well described in [11-20]. Some approach to calculating the risk priority number is based on fuzzy TOPSIS to the ideal solution [21-25]. They have adopted this technique in order to simplify and enhance the risk assessment procedures in traditional FMECA [26], taking advantage of the basic idea of TOPSIS that allows measurement of the Euclidean distance of an alternative from an ideal goal. To solve the problem of risk variable ranking, we apply fuzzy concepts related to linguistic variables and integrated with the TOPSIS to solve multicriteria problems. Procedures were gradually developed by referring to a combination of several studies that have been done. However, it does not eliminate the importance of the findings in this paper. This paper has found that the project objective, i.e., time, cost, and quality criteria, should be weighted to obtain the ranking of the risk variable. It differs from other studies in which they do not weight the project objectives, such as $[26,27]$.

Usually, the risk exists in construction projects due to uncertain events, which are inevitable or may effect on not only one of a project's objectives, as the triple constraint of the project, e.g., time, cost, and quality [15]. A risk variable can have a significant effect on a project objective but a low effect on other project objectives. This condition indicates there is a variation in the risk ranking of the risk variable illustrated by its influence on a project objective. This research proposes scale for criteria weight important (I) for cost, rather important (RI) for time, and less important (LI) for quality. It shows that each contractor can have different preferences for the three project objectives. However, the method proposed in this study to rank risk variable by considering the different weights of the costs, time, and quality in an integrated manner is a novelty. It can be applied for the same problems on different contexts of the research as the period of rehabilitation and reconstruction of posttsunami disaster, especially in Aceh-Indonesia. Risk analysis for 127 risk variables categorised into 14 factors using fuzzy TOPSIS methods conclude that labour factor is the most dominant variable affecting project risk in context the rehabilitation and reconstruction posttsunami disaster, especially in Aceh-Indonesia. The variables are lack of labour, unskilled labour, undisciplined labour, and low productivity of labour. The dominant factor is in line with Husin's previous research, which only examines the project objective of time [9]. We stated that integrating all three criteria of cost, time, and quality simultaneously is more logic to analyze risk variable ranking.

\section{Materials and Methods}

2.1. Multiple Criteria Decision-Making (MCDM). MCDM is known as a method to solve the multiple conflicting criteria in selecting the best ranking and providing an option from the feasible solution alternatives [24]. Some of the alternative cases are connected to MCDM criteria weight problem using a decision matrix as Koulinas's research [28]. In MCDM of classical methods, the rankings of variable and the weights of the criteria are known precisely in the papers $[15,19,25,27,29]$. Implementation for only TOPSIS (Technique for Order of Performance by Similarity to Ideal Solution) has been known as the classical MCDM method, and it was first introduced by Hwang to solve an MCDM problem $[24,30]$. The underlying TOPSIS logic is used to the ideal solution to maximise benefit and to minimise cost. In short, the ideal solutions are best values attainable of all criteria; meanwhile, the negative ideal solution is composing for all worst values attainable of decision criteria [30]. The optimal alternative consists of the shortest distance of the ideal solution and farthest distance of the negative ideal solution. In the TOPSIS, both the performance rankings and the weights of the criteria are known as crisp values. Since human judgments, including preferences, are often vague and cannot estimate his preference with an exact numerical value, crisp data are inaccurate to model real-life conditions. A realistic approach to convert the linguistic into the numerical values is assessed by linguistic variables $[11,24,30,31]$.

2.2. Fuzzy Sets. Fuzzy basic definitions were clearly reviewed in previous research [24, 32-36]. A function of fuzzy set is characterised by its membership function $\mu_{-} \grave{\mathrm{A}}(x)$. It is associated with each element $x$ in $X$ as a real number in the interval $(0 ; 1)$. The function value $\mu_{-} \grave{\mathrm{A}}(x)$ is termed the grade of membership of $x$ in $\tilde{A}$ [35], denoted as linguistic terms for variable values [35].

2.3. Research Framework. The framework, as shown in Figure 1, is utilised to rank the risk frequency of the alternative risk variables. The variables are identified from some of the literatures reviewed and expert judgments. The 


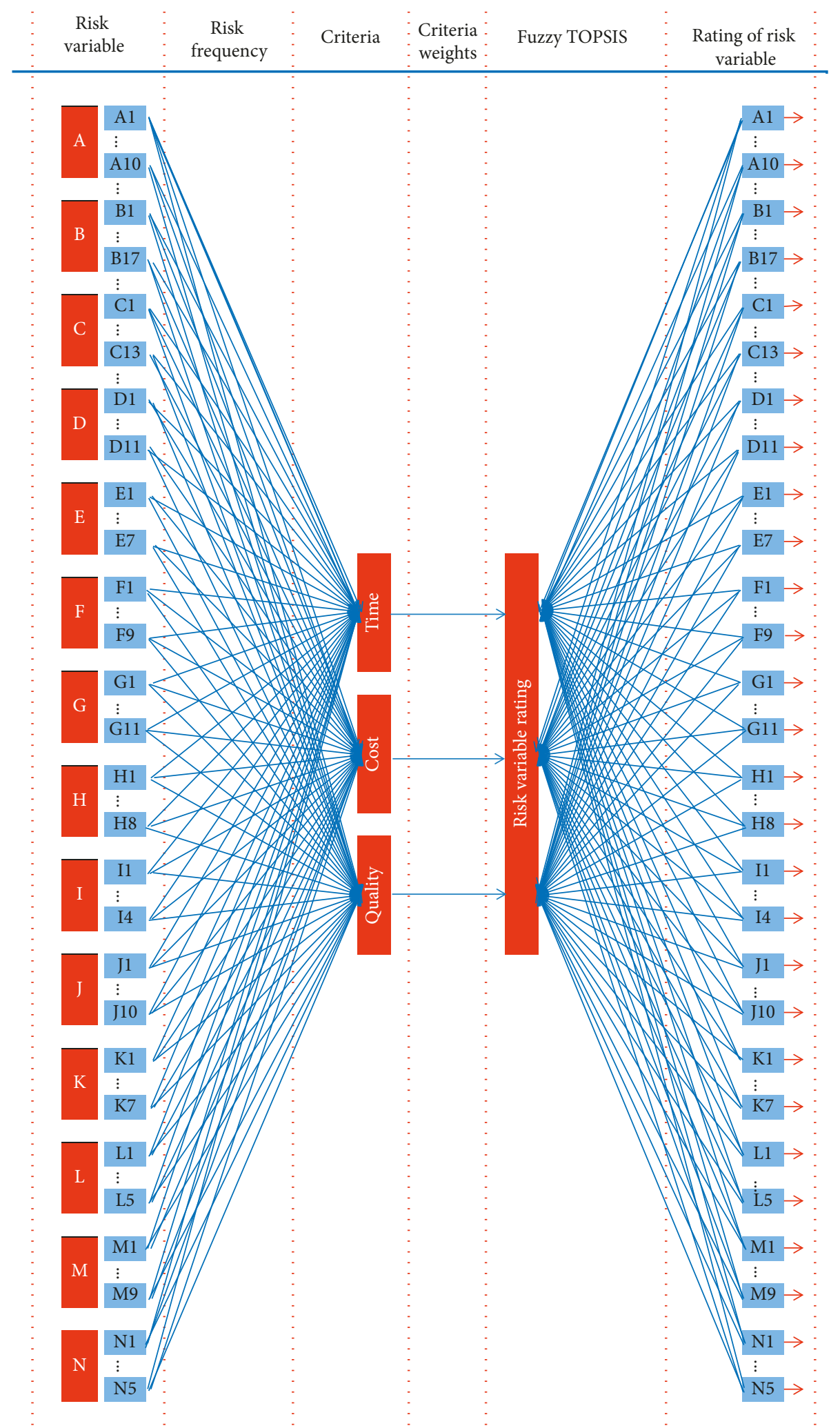

FIGURE 1: The framework of the research method.

risk variables are judged by the contractors with high qualification ever conducted the building construction during the reconstruction phase of the posttsunami disaster in Aceh-Indonesia. A framework for variable risk ranking is based on three criteria of time, cost, and quality. The input of the model is the frequency of risk variables from 15 respondents. This model showing a number 127 risk variable frequency by linguistic data will be processed to achieve a 
risk variable ranking, as shown in Figure 1. This model analysis is referred to as MCDM analysis (Formulas (1) and (2)).

2.4. Variable Scale and Criteria Scale. In this paper, the risk variable based on frequency constraint used as input of the risk variable ranking model is scaled based on linguistic scale, such as very low (VL), low (L), medium (M), high $(\mathrm{H})$, very high $(\mathrm{VH})$, as shown in Table 1 . The scale of the linguistic variable is converted to a fuzzy membership function.

The criteria, such as cost, time, and quality, is weighted based on expert judgment. The scale of criteria weights is very unimportant (VNI), less important (LI), rather important (RI), important (I), and very important (VI). This scale refers to the value weight of 0 to 1 . The criteria weight using a scale of linguistic weights is converted to fuzzy membership function, as shown in Table 2.

A weighted normalised fuzzy decision matrix is constructed for the decision-makers. In the concept of TOPSIS, the FPIS (fuzzy positive ideal solution) and the FNIS (fuzzy negative ideal solution) are defined and involved. We use Negi's method to calculate the distance between two triangular fuzzy rankings [34]. A closeness coefficient of each alternative is calculated to rank all of the alternatives. The higher value of closeness coefficient indicates closer to FPIS and farther FNIS simultaneously to the alternative.

An approach for the fuzzy environment is proposed to extending the TOPSIS in this paper, as the previous research of decision-making problem under fuzzy environment $[24,36]$. Linguistic variables are used to analyze the ranking value of variable and criteria weights by considering the fuzziness of data. Based on the upper and lower mechanisms, the FMCDM-TOPSIS is generated into a fuzzy number, as shown in Tables 1 and 2, successfully for the frequency of risk variable and the weights of criteria.

2.5. Decision Matrix of MCDM. Developing the decision matrix model for the alternative is based on $\{m \times n\}$, where $m$ and $n$ successfully are the numbers of alternative and the criteria weights; in this case, $\{127 \times 3\}$ is a matrix, as expressed in a matrix in formula (1). Meanwhile, criteria weights are expressed in a matrix in formula (2) as follows:

$$
\begin{aligned}
\text { Alternative } & =\left[\begin{array}{ccc}
x_{11} & x_{12} & x_{13} \\
x_{21} & x_{22} & x_{23} \\
\vdots & \vdots & \vdots \\
x_{m 1} & x_{m 2} & x_{m 3}
\end{array}\right], \\
\text { Criteria weight } & =\left[\begin{array}{c}
w_{1} \\
w_{2} \\
w_{3}
\end{array}\right] .
\end{aligned}
$$

The alternative of the decision matrix is represented by $x_{i j}$, as risk variables obtained from formula (3), and notation $w_{j}$ is the criteria weights obtained from formula (4) as cost, time, and quality. Meanwhile, $K$ is the number of respondents:

$$
\begin{aligned}
& x_{i j}=\frac{1}{K}\left(x_{i j}^{1}+x_{i j}^{2}+\cdots+x_{i j}^{K}\right), \\
& w_{j}=\frac{1}{K}\left(w_{j}^{1}+w_{j}^{2}+\cdots+w_{j}^{K}\right) .
\end{aligned}
$$

2.6. Fuzzy Multiple Criteria Decision-Making (FMCDM). In case of avoiding the complicated normalisation of the formula, the classical TOPSIS is used to linear scale transformation to transform the criteria scales into the comparable scale. Therefore, the normalised fuzzy decision matrix, as the following formula, could be developed in this research:

$$
\text { Alternative (fuzzy) }=\left[\begin{array}{ccc}
r_{11} & r_{12} & r_{13} \\
r_{21} & r_{22} & r_{23} \\
\vdots & \vdots & \vdots \\
r_{m 1} & r_{m 2} & r_{m 3}
\end{array}\right] \text {. }
$$

Analysis of risk variable ranking is calculated using the following formula summarised from formula (10):

$$
\text { Criteria weigh (fuzzy) }\left(V_{i}\right)=r_{i j} \cdot w_{j}=\left[\begin{array}{c}
v_{1} \\
v_{2} \\
\vdots \\
v_{m}
\end{array}\right] \text {, }
$$

where the element matrix $r_{i j}$ is obtained by using the following formula (7) to formula (8) by adjustment, benefit or attribute of the criteria is

$$
\left\{\begin{array}{l}
r_{i j}=\frac{x_{i j}}{x_{j}^{*}}, \quad \forall j, x_{j} \ldots \text { benefit } \ldots \text { attribute } \\
r_{i j}=\frac{x_{j}^{-}}{x_{i j}}, \quad \forall j, x_{j} \ldots \text { cost } \ldots \text { attribute }
\end{array}\right.
$$

where $x_{j}^{*}=\max _{i} x_{i j}$ and $x_{j}^{-}=\min _{i} x_{i j}$.

The formula above is then replaced by the fuzzy operations $\quad x_{i j}=\left(a_{i j}, b_{i j}, c_{i j}\right) ; \quad x_{j}^{*}=\left(a_{j}^{*}, b_{j}^{*}, c_{j}^{*}\right) \quad$ and $x_{j}^{-}=\left(a_{j}^{-}, b_{j}^{-}, c_{j}^{-}\right)$, so it can be expressed as the following formula:

$$
\left\{\begin{array}{l}
r_{i j}=\frac{x_{i j}}{x_{j}^{*}}=\left(\frac{a_{i j}}{\overrightarrow{c_{j}}} ; \frac{b_{i j}}{b_{j}} ; \frac{c_{i j}}{\overrightarrow{a_{j}}}\right), \quad \longleftrightarrow \text { for } \longrightarrow \text { benefit }, \\
r_{i j}=\frac{x_{j}^{-}}{x_{i j}}=\left(\frac{a_{j}^{-}}{c_{i j}} ; \frac{b_{j}^{-}}{b_{i j}} ; \frac{c_{j}^{-}}{a_{i j}}\right),
\end{array}\right.
$$

where $x_{i j}, \forall i, j$ and $w_{j}, j=1,2, \ldots, n$ are the linguistic variables described by using the triangular fuzzy numbers, $\tilde{x}_{i j}=\left(a_{i j}, b_{i j}, c_{i j}\right)$, as shown in Table 1 , and $w_{i j}=\left(w_{j 1}, w_{j 2}\right.$, $\left.w_{j 3}\right)$, in Table 2 .

2.7. Normalised Fuzzy Multiple Criteria Decision-Making (Normalised FMCDM). The normalisation method is used 
TABLE 1: Linguistic for the risk frequency of each risk variable.

\begin{tabular}{lcl}
\hline $\begin{array}{l}\text { Linguistic } \\
\text { variable scale }\end{array}$ & $\begin{array}{c}\text { Membership of } \\
\text { fuzzy number }\end{array}$ \\
\hline Very low (VL) & $(0 ; 1 ; 2)$ \\
Low (L) & $(1 ; 2 ; 3)$ \\
Medium (M) & $(2 ; 3 ; 4)$ \\
High (H) & $(3 ; 4 ; 5)$ & $(4 ; 5 ; 5)$
\end{tabular}

TABLE 2: Linguistic for important criteria weights.

\begin{tabular}{lcl}
\hline Linguistic variable scale & Membership of fuzzy number \\
\hline Very unimportant (VNI) & $(0.0 ; 0.2 ; 0.4)$ \\
Less important (LI) & $(0.2 ; 0.4 ; 0.6)$ \\
Rather important (RI) & $(0.4 ; 0.6 ; 0.8)$ \\
Important (I) & $(0.6 ; 0.8 ; 1.0)$ \\
Very important (VI) & $(0.8 ; 1.0 ; 1.0)$ & - Ress important (LI) \\
\hline
\end{tabular}

to construct the weighted normalised fuzzy decision matrix as formula (9). This normalisation method is conducted by preserving the property of triangular of fuzzy numbers of $(0$, 1):

$$
V=\left\{v_{i j}\right\}_{m x n} \quad i=1,2, \ldots, m, j=1,2, \ldots, n,
$$

where $v_{i j}\left(r_{i j} \cdot w_{j}\right)$ is the fuzzy membership, which is expressed by the following fuzzy operations using formula (10); meanwhile, the membership of $w_{j}$ is $\left(w_{1 j}, w_{2 j}, w_{3 j}\right)$ :

$$
\left\{\begin{array}{l}
v_{i j}=r_{i j} \cdot w_{j}=\left(\frac{a_{i j}}{c_{j}^{*}} \alpha_{j} ; \frac{b_{i j}}{b_{j}^{*}} \beta_{j} ; \frac{c_{i j}}{a_{j}^{*}} \gamma_{j}\right), \\
v_{i j}=r_{i j} \cdot w_{j}=\left(\frac{a_{j}^{-}}{c_{i j}} \alpha_{j} ; \frac{b_{j}^{-}}{b_{i j}} \beta_{j} ; \frac{c_{j}^{-}}{a_{i j}} \gamma_{j}\right) .
\end{array}\right.
$$

2.8. Ranking Methods. The ranking method for the risk variable refers to Chen [36] cited from Lee and Li's ranking method, in which for fuzzy data, $V_{j}^{*}$ and $V_{j}^{-}$may be obtained through some ranking procedures by comparing the fuzzy numbers. The $V_{j}^{*}$ and $V_{j}^{-}$are the fuzzy numbers with the most significant generalized mean and the smallest, respectively. The generalized mean for triangular fuzzy

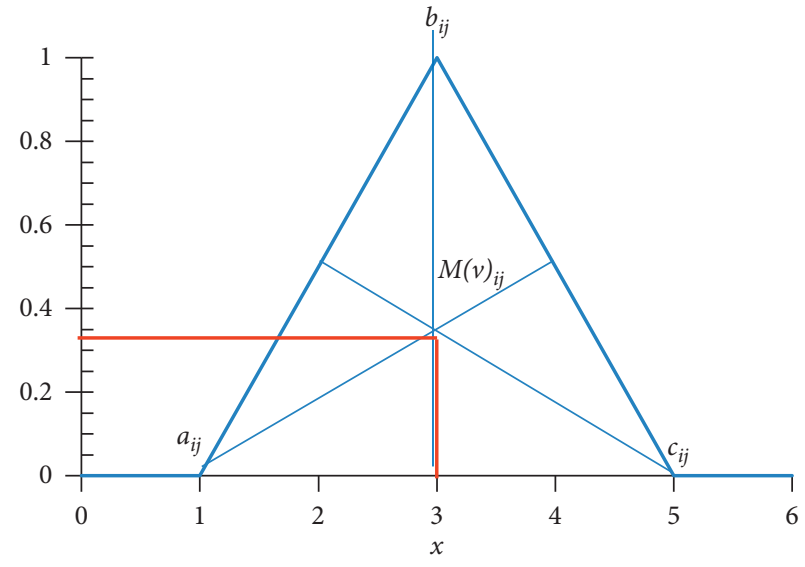

FIgURE 2: The generalized mean for TFN.

number (TFN) is $M\left(V_{i j}\right)$ (Figure 2). To calculate $M\left(V_{i j}\right)$, the following formula is used:

$$
M\left(v_{i j}\right)=\left(\frac{-a^{2}+c_{i j}^{2}-a_{i j}+c_{i j} \cdot b_{i j}}{3\left(-a_{i j}+c_{i j}\right)}\right),
$$

where $M\left(V_{i j}\right), \forall i, j, V_{i j}$ has the most significant mean as $V_{j}$ and the lowest mean as $V_{j}^{-}$, so the fuzzy positive ideal solution (FPIS), $A^{*}$, and fuzzy negative ideal solution (FNIS), $A^{-}$, can be arranged as shown in formulas (12) and (13), respectively: 


$$
\begin{aligned}
A^{*} & =\left(v_{1}^{*}, v_{2}^{*}, \ldots, v_{n}^{*}\right), \\
A & =\left(v_{1}^{-}, v_{2}^{-}, \ldots, v_{n}^{-}\right) .
\end{aligned}
$$

The intersection of two memberships referring to five scales, either the alternative (risk variable) using Table 1 and weight criteria (cost, time, and quality) using Table 2, is calculated using Figures 3(a) and 3(b). According to the figures, $L_{i j}$ is the highest degree of similarity between $V_{i j}$ and $v_{j}^{*}$ or the lowest degree of similarity between $V_{i j}$ and $v_{j}^{-}$. By solving numerically, the intersection point of $L_{i j}$ of both fuzzy membership numbers and, then, the difference between two memberships $\left(D_{i j}^{*}\right.$ and $D_{i j}^{-}$) can be expressed mathematically as shown in formulas (14) and (15), respectively:

$$
\begin{gathered}
D_{i j}^{*}= \begin{cases}1-\frac{c_{i j}-a_{j}^{*}}{b_{j}^{*}+c_{i j}-a_{j}^{*}-b_{i j}} & \longleftrightarrow \text { for } \longrightarrow b_{i j}<b_{j}^{*}, \\
1-\frac{c_{j}^{*}-a_{i j}}{b_{i j}+c_{j}^{*}-a_{i j}-b_{j}^{*}} & \longleftrightarrow \text { for } \longrightarrow b_{j}^{*}<b_{i j},\end{cases} \\
D_{i j}^{-}= \begin{cases}1-\frac{c_{i j}-a_{j}^{-}}{b_{j}^{-}+c_{i j}-a_{j}^{-}-b_{i j}} & \longleftrightarrow \text { for } \longrightarrow b_{i j}<b_{j}^{-}, \\
1-\frac{c_{j}^{-}-a_{i j}}{b_{i j}+c_{j}^{-}-a_{i j}-b_{j}^{-}} & \longleftrightarrow \text { for } \longrightarrow b_{j}^{-}<b_{i j},\end{cases}
\end{gathered}
$$

where the values of $D_{i j}^{*}$ and $D_{i j}^{-}$are the crisp number.

Then, obtain the separation measures $S_{i j}^{*}$ and $S_{i j}^{-}$. In the classical case, separation measures are defined, as shown in formulas (16) and (17), respectively:

$$
\begin{aligned}
& S_{i j}^{*}=\sum_{j=1}^{n} D_{i j}^{*}, \quad \text { for } i=1, \ldots, m, \\
& S_{i j}^{-}=\sum_{j=1}^{n} D_{i j}^{-}, \quad \text { for } i=1, \ldots, m .
\end{aligned}
$$

2.9. Closeness Coefficient Index (CCI). Finally, compute the relative closeness to the ideals or closeness coefficient index (CCI). This index is used to combine $S_{i j}^{*}$ and $S_{i j}^{-}$indices in formulas (16) and (17). Since $S_{i j}^{*}$ and $S_{i j}^{-}$are thr crisp numbers, they can be combined in order to determine the ranking order of all alternatives referring to the values of $S_{i}^{*}$ and $S_{i}^{-}$for each alternative $A_{i}(i=1,2, \ldots, m)$ using the following formula:

$$
\mathrm{CC}_{\mathrm{I}}=\frac{S_{i j}^{-}}{S_{i j}^{*}-S_{i j}^{-}}, \quad \text { for } i=1,2, \ldots, m .
$$

Problem risk variable ranking influencing the project objective is modelled based on the criteria weight, namely, time, cost, and quality. The framework, as shown in Figure 1, shows that three criteria and 127 alternatives of 14 factors, $A$ to $N$, are be evaluated toward 15 contractors experiencing in the historical events. The step to solving this problem is as follows:

Step 1. Data collection from respondents' judgment for the frequency of risk variable, see Table 4 in the Supplementary Material.

Step 2. The data collected from respondents judgment, see Table 4 in the Supplementary Material, is converted to membership of the fuzzy number for frequency risk variables, see Table 5 in the Supplementary Material.

Step 3. Obtaining the fuzzy decision matrix for all three criteria, which is each element of the matrix of TFN is calculated using the mean arithmetic method and the results, see Table 6 in the Supplementary Material.

Step 4. Constructing the normalised fuzzy of risk frequency matrix, an element matrix, is obtained by adjusting with benefits or cost attribute of criteria as in formula (7). The results are shown in Table 7 of the Supplementary Material.

Step 5. Normalised fuzzy of the criteria weight for time, cost, and quality is Important (I), Rather Important (RI), and Less Important (LI). The results are shown in Table 8 of the Supplementary Materials.

Step 6. Multiplication of the alternative matrix and the weight matrix, see Table 9 in the Supplementary Material. The decision matrix contains crisp data assumed as the linguistic terms, and it can be represented by TFN.

Step 7. Obtaining fuzzy positive and negative ideal solutions (FPIS and FNIS). First, $M\left(V_{i j}\right)$ is computed using formula (11), and then it is compared with the values, see Table 9 in the Supplementary Material. For the fuzzy positive ideal solution (FPIS) and the fuzzy negative ideal solution (FNIS), see Table 10 in the Supplementary Material.

Step 8. Based on the results of FPIS and FNIS, the distance will be calculated by calculating the differences $D_{i j}^{*}$ and $D_{i j}^{-}$. It can be calculated using formulas (14) and (15), and separation measures $S_{i j}^{*}$ and $S_{i j}^{-}$are calculated using formulas (16) and (17); then to obtain the closeness coefficient index (CCI) of each alternative, formula (18) is used as summarised in Table 11 in the Supplementary Material.

Step 9. Finally, from FPIS and FNIS, the differences $D_{i j}^{*}$ and $D_{i j}^{-}$can be calculated using formulas (14) and (15), and separation measures $S_{i j}^{*}$ and $S_{i j}^{-}$are calculated using formulas (16) and (17), and to obtain the closeness coefficient index (CCI) of each alternative, formula (18) is used as summarised in Table 11 in the Supplementary Materials.

\section{Results and Discussion}

3.1. Risk Variable Ranking. The hierarchical structure of the risk variable ranking problem of the project shown in 


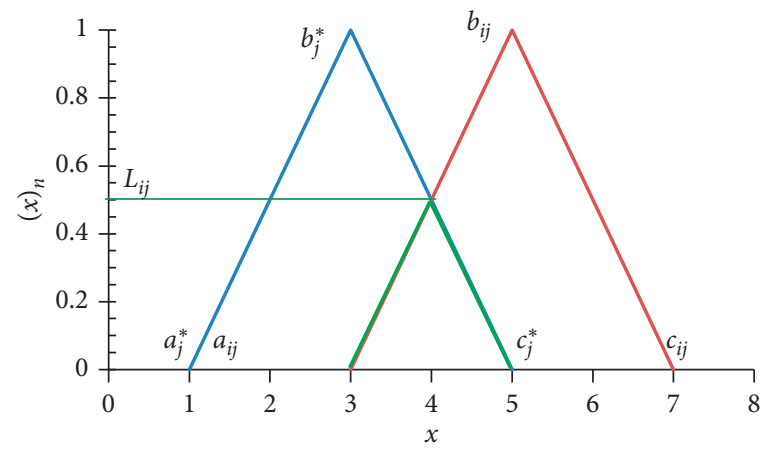

(a)

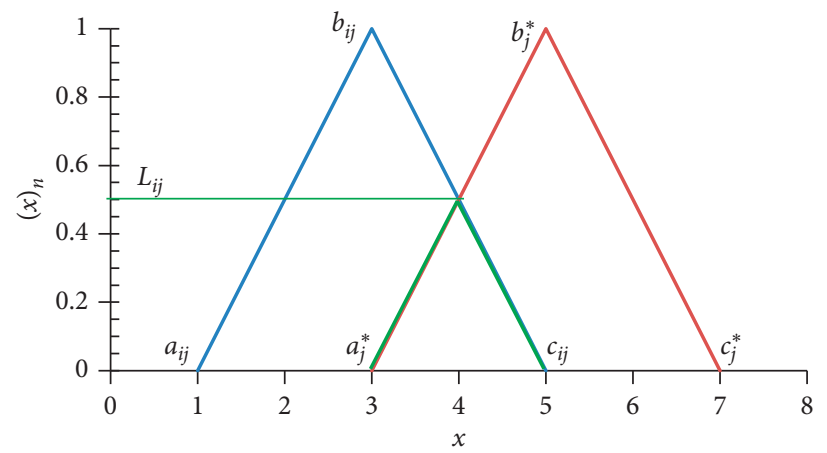

(b)

Figure 3: The intersection of two memberships $\left(L_{i j}\right)$.

Figure 1 is analysed using nine steps as a computational procedure. These models consist of three components as follows:

(i) The three criteria utilised in the proposed model are cost $(\mathrm{C} 1)$, time (C2), and quality (C3)

(ii) This research uses 127 risk variables distributed in 14 factors ( $A$ to $N$ )

(iii) Respondent judgment as a linguistic variable is obtained from 15 companies in Aceh-Indonesia (E1 to $E 15)$

Ranking for 127 variables is based on ranking on the highest score of closeness coefficient index to the low score. Analysis close coefficient index as the step to achieve the closeness coefficient index. The result of the risk variable rank is given in Table 12 of the Supplementary Material.

3.2. Comparison to Other Research. This study has developed a risk analysis by considering three criteria as a basis for ranking risk variables using the fuzzy TOPSIS approach. This research is different from the general risk research, which considers costs, time, and quality partially as the possibility of unreachable project objectives caused by risk variables. The multicriteria concept in this study is based on the project objectives of cost, time, and project quality as the basis for conducting variable risk ranking. This study considers costs, time, and quality as criteria that are directly involved and integrated into risk analysis by giving weight to each of these criteria. The use of integrated criteria weights for multiobjective decision-making can be effective, as other studies also use criteria weights $[37,38]$. Integrating simultaneously 3 project objectives in risk variable ranking is based on that each contractor has different preferences for the three project objectives. The criteria weight from expert judgment, as weights for costs, time, and quality, respectively, are scaled as important (I), rather important (RI), less important (LI), see Table 8 in the Supplementary Material. Assessment for alternatives, in this case, variable risk, is assessed by contractors who have worked in the context of the reconstruction of posttsunami disaster in Aceh-Indonesia, as respondents.

Although, there are many multicriteria decision analysis (MCDA) that use criteria weights as a basis for determining the ranking of alternatives (in this case, the variable rank of risk), as in the study of Fachrurrazi et al. [39]. However, the study has not considered various expert judgments as for the linguistic variable and the linguistic alternative. This study considers fuzzy concepts for MCDM problems. The relevant research had been conducted on ratings on variables such as Liu and Wei [40], but they are not explicitly analysed based on the weights of the project objectives, but on 17 other criteria. This study fills the gap of the study, where alternatives considered for cost, time, and quality risk are given in Table 12 of the Supplementary Material, with the highest range of top ten variables, as summarised in Table 3. Another relevant research using analytic hierarchy process (AHP) such as Nazam et al. [41] has been done on risk assessments of green raw material, but they use risk variable as criteria of decision problems, which are different from this research that uses project objective as criteria to rank the risk variable.

3.3. Top Ten Risk Variables. The result of the rank analysis of 127 risk variables that contribute to the probability of project risk to the three objectives of the construction project in an integrated manner of costs, time, and quality can be determined, and for the significant sequence of the possibility or probability of variables, see Table 12 in the Supplementary Material. The top ten risk variables in the highest order are shown in Table 3. Based on the top ten variable rankings, we conclude that labour factor consists of the dominant variable affecting project risk in context the rehabilitation and reconstruction posttsunami disaster in Aceh-Indonesia. This condition can differ based on different risk contexts.

This factor is the first rank in the ranking of risk factors, as shown in Table 3. The risk variables included in the top ten can vary depending on the effect on the three proposed criteria, namely, for the cost, time, and quality criteria. However, the variable with the highest number is factor $E$, which is four variables, respectively, E2, E3, E1, and E4. Labour is the primary resource regarding support of other project resources. Contractors who handle large amounts of work, of course, require much labour.

The posttsunami disaster of Aceh-Indonesia was reconstructed of 101,000 housing units, 95,000 units needed to be rehabilitated; meanwhile, most of the infrastructure 
TABLE 3: The top ten risk variables.

\begin{tabular}{lccc}
\hline Name of risk factor & Code of risk factor & Risk factor & Closeness index \\
\hline Unskilled labour [9] & E2 & Labour & 0.848 \\
Electricity problem & G3 & Operational & 0.837 \\
Undisciplined labour [9] & E3 & Labour & 2 \\
Lack of labour [9] & E1 & Labour & 0.802 \\
Self-protect instruments of a construction worker & H3 & Health and safety of work & 0.759 \\
Low productivity of labour [9] & E4 & Labour & 0.751 \\
Fuel scarcity [9] & B9 & Equipment & 0.747 \\
Broken equipment [9] & B5 & Equipment & 0.695 \\
Less experience of the contractor & F3 & Contractor managerial & 0.691 \\
The delay in material delivery [9] & A2 & Material & 0.690 \\
\hline
\end{tabular}

was destroyed [42]. The significant destruction totalled up to about $97 \%$ of Province's GDP [43]. This condition illustrates that during this period, there were severe problems with the rehabilitation and reconstruction process. To carry out the process of rehabilitation and reconstruction with a massive number of projects, substantially, contractors need construction workers, as well. On the contrary, limited resources can lead to competition between contractors. It is implicated on the contractor's high risk to handle a large number of projects at the same time. It is in line with Zecola [44] which stated that the lack of labour due to death during the tsunami and the high level of rehabilitation carried out in the area of Aceh is the main problem condition.

Skilled labour is the primary resource for the construction project. Skilled labours, both from physical skills or project administration skills in Aceh-Indonesia after the tsunami, died in the tsunami disaster, and some were disabled or traumatic. This condition caused a shortage of skilled labours during the rehabilitation and reconstruction period. This condition encourages to bring the skilled workers from outside of Aceh, causing an over mobilisation cost, time, and quality. Some contractors who handle large amounts of work, which are needed at that time, face complex management risks. The competition of some contractors to fight for labour is a separate problem which causes workers' wages to increase.It is related to the reason in Fachrurrazi's paper which stated that the NGOs and Indonesian Government provide the programme for reconstructing and rebuilding the devastated community sector, such as the people capacity, the livelihoods, the social fabric, and especially construction worker sector, to speed up infrastructure recovery [43]. These research results show that the variables in the top ten rankings are dominated by labour $(E)$ factor; they are $E 1, E 2, E 3$, and $E 4$. Based on this condition, we state that in the context of the implementation of rehabilitation and reconstruction in disaster areas, many victims need to consider the labour factor as constructive in disaster management because it can pose risks toward time, cost, and quality.

\section{Conclusions}

In this paper, we have ranked 127 variables of risk frequency based on the criteria weight for a time, cost, and quality simultaneously, as the triple constraints, using the fuzzy TOPSIS approach. This concept is different from other studies which generally use individually for each criterion of cost, time, or quality for the basis of the ranking of the project risk variables. For integrating the three objectives of this project to be used as a ranking basis, of course, it requires modification of a particular risk analysis technique by implementing the project objective to be the criteria weight referring to the multicriteria decision analysis (MCDA) technique. The method proposed is a novelty of this study. Based on the weight of the criteria applied in this case, it shows that the cost criteria are the most important than the two others, followed by the time criteria, and the later is the quality criteria, which are, respectively, important (I), rather important (RI), and less important (LI). It shows that each contractor can have different preferences for the three project objectives.

The risk variable using the proposed approach has successfully been sorted from rank 1 to 127 . Based on the top ten rankings of the risk variable, 4 of the ten variables indicate that factor labour $(E)$ dominates from another factor, namely, unskilled labour, undisciplined labour, lack of labour, and low productivity of labour. These results can be possible in the context of the risks of the rehabilitation and reconstruction of the posttsunami disaster in Aceh-Indonesia. Although, the method, the proposed problem-ranking paper for risk variables, however, can also be applied to other problems in project construction and many other areas of management decision problems, especially in risk analysis problems.

\section{Data Availability}

The data used to support the findings of this study are included within the supplementary information file.

\section{Conflicts of Interest}

The authors declare that there are no conflicts of interest regarding the publication of this paper.

\section{Acknowledgments}

The authors would like to appreciate various parties involved in this research, especially, Construction Engineering and Management Laboratory, Civil Engineering Department, Universitas Syiah Kuala, for providing support for this research. The research and publication of this article were fully self-funded. 


\section{Supplementary Materials}

The tabulation datasets.doc (Word Doc) used to support the findings of this study are included within the supplementary information file. (Supplementary Materials)

\section{References}

[1] N. Lavanya and T. Malarvizhi, "Risk analysis and management: a vital key to effective project management," in Proceedings of the PMI ${ }^{\circledR}$ Global Congress 2008-Asia Pacific, Project Management Institute, Sydney, Australia, March 2008.

[2] F. Fachrurrazi, S. Husin, and M. Mahmuddin, "Project risk patterns: a comparison across three periods," International Journal on Advanced Science, Engineering and Information Technology, vol. 8, no. 5, p. 1997, 2018.

[3] P. L. Bannerman, "Risk and risk management in software projects: a reassessment," Journal of Systems and Software, vol. 81, no. 2, pp. 2118-2133, 2018.

[4] F. Fachrurrazi, "The end user requirement for project management software accuracy," International Journal of Electrical and Computer Engineering (IJECE), vol. 8, no. 2, pp. 1112-1121, 2018.

[5] S. Firdose and L. M. Rao, "3LRM-3 layer risk mitigation modelling of ICT software development projects," International Journal of Electrical and Computer Engineering (IJECE), vol. 6, no. 1, pp. 349-356, 2016.

[6] S. Mubarak, H. Husin, and M. Oktaviani, "External risk factors affecting construction costs," AIP Conference Proceedings, vol. 1903, no. 1, article 110005, 2017.

[7] S. Husin, A. Abdullah, M. Riza, and M. Afifuddin, "Construction cost impacts related to manpower, material, and equipment factors in contractor firms perspective," AIP Conference Proceedings, vol. 1903, no. 1, article 110007, 2017.

[8] M. F. Diab, A. Varma, and K. Nassar, "Using risk assessment to improve highway construction project performance," in Proceedings of the 48th ASC Annual International Conference, Birmingham, UK, April 2012.

[9] S. Husin, A. Abdullah, M. Riza, and M. Afifuddin, "Risk assessment of resources factor in affecting project time," Advances in Civil Engineering, vol. 2018, Article ID 6896141, 9 pages, 2018.

[10] M. Grzywinski, T. Dede, and Y. I. Ozdemir, "Optimization of the braced dome structures by using Jaya algorithm with frequency constraints," Steel And Composite Structures, vol. 30, no. 1, pp. 47-55, 2019.

[11] W. Hadikurniawati and K. Mustofa, "Multicriteria group decision making using fuzzy approach for evaluating criteria of electrician," International Journal of Electrical and Computer Engineering (IJECE), vol. 6, no. 5, p. 2462, 2016.

[12] M. Askari and H. R. Shokrizade, "An integrated method for ranking of risk in BOT projects," Procedia-Social and Behavioral Sciences, vol. 109, pp. 1390-1394, 2014.

[13] O. Taylan, A. O. Bafail, R. M. S. Abdulaal, and M. R. Kabli, "Construction projects selection and risk assessment by fuzzy AHP and fuzzy TOPSIS methodologies," Applied Soft Computing, vol. 17, pp. 105-116, 2014.

[14] Y.-C. Kuo and S.-T. Lu, "Using fuzzy multiple criteria decision making approach to enhance risk assessment for metropolitan construction projects," International Journal of Project Management, vol. 31, no. 4, pp. 602-614, 2013.
[15] P. Rezakhani, "Fuzzy MCDM model for risk factor selection in construction projects," Engineering Journal, vol. 16, no. 5, pp. 79-94, 2012.

[16] R. Tavakkoli-Moghaddam, S. M. Mousavi, and H. Hashemi, "A fuzzy comprehensive approach for risk identification and prioritization simultaneously in EPC projects," in Risk Management in Environment, Production, and Economy, InTech, London, UK, 2011.

[17] A. Karimiazari, N. Mousavi, S. F. Mousavi, and S. Hosseini, "Risk assessment model selection in construction industry," Expert Systems with Applications, vol. 38, no. 8, pp. 9105-9111, 2011.

[18] E. K. Zavadskas, Z. Turskis, and J. Tamošaitienė, "Risk assessment of construction projects," Journal of Civil Engineering and Management, vol. 16, no. 1, pp. 33-46, 2010.

[19] T. Zayed, M. Amer, and J. Pan, "Assessing risk and uncertainty inherent in Chinese highway projects using AHP," International Journal of Project Management, vol. 26, no. 4, pp. 408-419, 2008.

[20] P. X. W. Zou, G. Zhang, and J. Wang, "Understanding the key risks in construction projects in China," International Journal of Project Management, vol. 25, no. 6, pp. 601-614, 2007.

[21] R. Zwick, E. Carlstein, and D. V. Budescu, "Measures of similarity among fuzzy concepts: a comparative analysis," International Journal of Approximate Reasoning, vol. 1, no. 2, pp. 221-242, 1987.

[22] M. Braglia, M. Frosolini, and R. Montanari, "Fuzzy TOPSIS approach for failure mode, effects and criticality analysis," Quality and Reliability Engineering International, vol. 19, no. 5, pp. 425-443, 2003.

[23] D. Walczak and A. Rutkowska, "Project rankings for participatory budget based on the fuzzy TOPSIS method," European Journal of Operational Research, vol. 260, no. 2, pp. 706-714, 2017.

[24] C.-T. Chen, "Extensions of the TOPSIS for group decisionmaking under fuzzy environment," Fuzzy Sets and Systems, vol. 114, no. 1, pp. 1-9, 2000.

[25] C.-L. Hwang and K. Yoon, "Multiple attribute decision making: methods and applications a state-of-the-art survey," in Springer Science \& Business Media, vol. 186, Springer, Berlin, Germany, 2012.

[26] Z. Xu, Y. Zhang, and H. Su, "Risk evaluation approach and application research on fuzzy-FMECA method based on cloud model," TELKOMNIKA Indonesian Journal of Electrical Engineering, vol. 12, no. 2, 2014.

[27] S. Ebrahimnejad, S. M. Mousavi, and S. M. H. Mojtahedi, "A model for risk evaluation in construction projects based on fuzzy MADM," in Proceedings of the 4th IEEE International Conference on Management of Innovation and Technology, pp. 305-310, IEEE, Bangkok, Thailand, September 2008.

[28] G. K. Koulinas, O. E. Demesouka, P. K. Marhavilas, A. P. Vavatsikos, and D. E. Koulouriotis, "Risk assessment using fuzzy TOPSIS and PRAT for sustainable engineering projects," Sustainability, vol. 11, no. 3, p. 615, 2019.

[29] F. Fachrurrazi, Y. Away, and S. Husin, "The weights detection of multi-criteria by using solver," International Journal of Electrical and Computer Engineering (IJECE), vol. 7, no. 2, pp. 858-868, 2017.

[30] Y.-J. Wang and H.-S. Lee, "Generalizing TOPSIS for fuzzy multiple-criteria group decision-making," Computers \& Mathematics with Applications, vol. 53, no. 11, pp. 1762-1772, 2007. 
[31] M. Delgado, J. L. Verdegay, and M. A. Vila, "Linguistic decision-making models," International Journal of Intelligent Systems, vol. 7, no. 5, pp. 479-492, 1992.

[32] J. J. Buckley, "Fuzzy hierarchical analysis: the Lambda-Max method," Fuzzy sets and systems, vol. 17, no. 3, pp. 233-247, 1985.

[33] M. Kaufmann and A. Gupta, Introduction to Fuzzy Arithmetics: Theory and Applications, Van Nostrand Reinhold Co., New York, NY, USA, 1991.

[34] D. S. Negi and E. Stanley Lee, "Possibility programming by the comparison of fuzzy numbers," Computers \& Mathematics with Applications, vol. 25, no. 9, pp. 43-50, 1993.

[35] L. A. Zadeh, "The concept of a linguistic variable and its application to approximate reasoning-I," Information Sciences, vol. 8, no. 3, pp. 199-249, 1975.

[36] S.-J. Chen and C.-L. Hwang, Fuzzy Multiple Attribute Decision Making Methods, Springer, Berlin, Germany, 1992.

[37] T. Dede, "Jaya algorithm to solve single objective size optimization problem for steel grillage structures," Steel And Composite Structures, vol. 26, no. 2, pp. 163-170, 2018.

[38] F. Fachrurrazi, A. Abdullah, Y. Away, and T. B. Aulia, "Negative total float to improve a multi-objective integer nonlinear programming for project scheduling compression," International Journal of Electrical and Computer Engineering (IJECE), vol. 8, no. 6, pp. 5292-5302, 2018.

[39] F. Fachrurrazi, S. Husin, Munirwansyah, and Husaini, "The subcontractor selection practice using ANN-multilayer," International Journal of Technology, vol. 8, no. 4, pp. 761-772, 2017.

[40] J. Liu and Q. Wei, "Risk evaluation of electric vehicle charging infrastructure public-private partnership projects in China using fuzzy TOPSIS," Journal of Cleaner Production, vol. 189, pp. 211-222, 2018.

[41] M. Nazam, J. Xu, Z. Tao, J. Ahmad, and M. Hashim, “A fuzzy AHP-TOPSIS framework for the risk assessment of green supply chain implementation in the textile industry," International Journal of Supply and Operations Management, vol. 2, no. 1, pp. 548-568, 2015.

[42] F. Steinberg, "Housing reconstruction and rehabilitation in Aceh and Nias, Indonesia-Rebuilding lives," Habitat International, vol. 31, no. 1, pp. 150-166, 2007.

[43] BAPPENAS, Indonesia: Preliminary Damage and Loss Assessment, BAPPENAS, Central Jakarta, Indonesia, 2005.

[44] P. Zeccola, "Dividing disasters in Aceh, Indonesia: separatist conflict and tsunami, human rights and humanitarianism," Disasters, vol. 35, no. 2, pp. 308-328, 2011. 


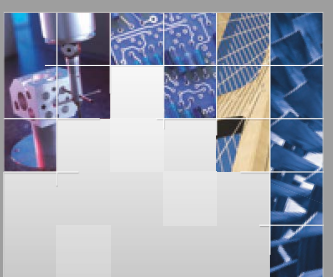

\section{Enfincering}
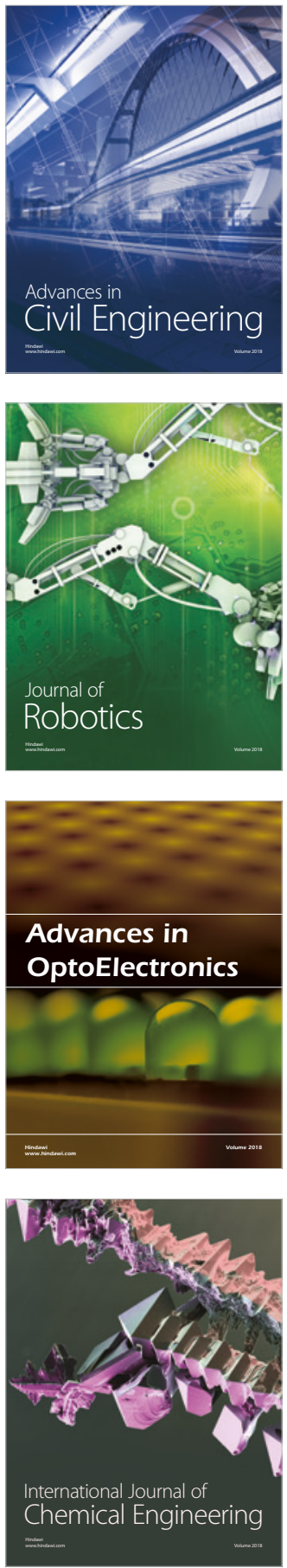

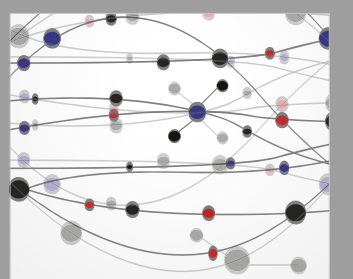

\section{Rotating \\ Machinery}

The Scientific World Journal

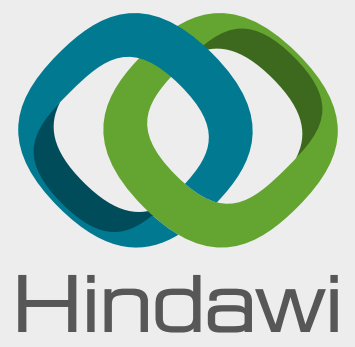

Submit your manuscripts at

www.hindawi.com
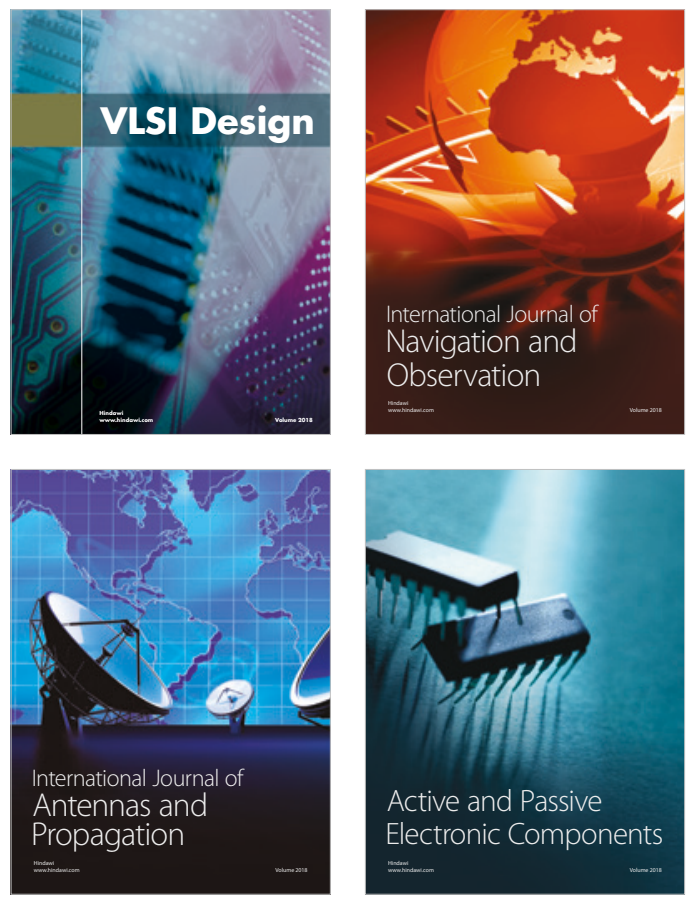
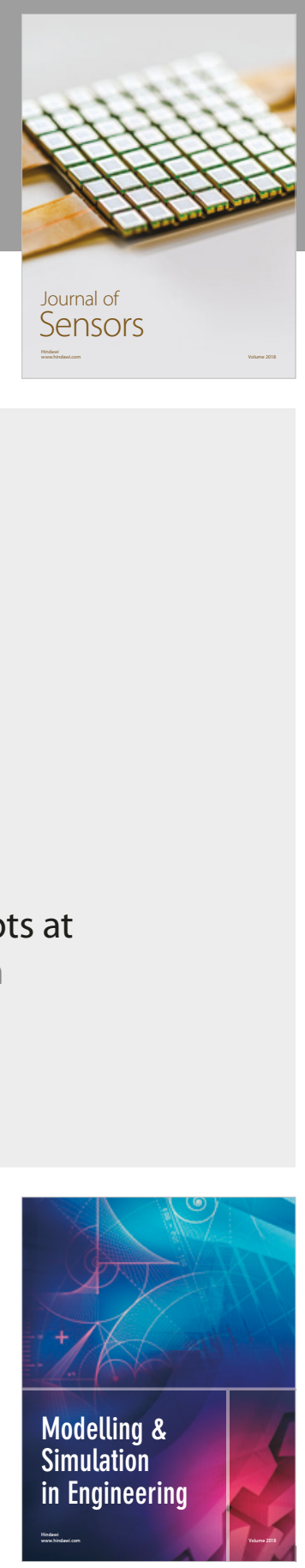

\section{Advances \\ Multimedia}
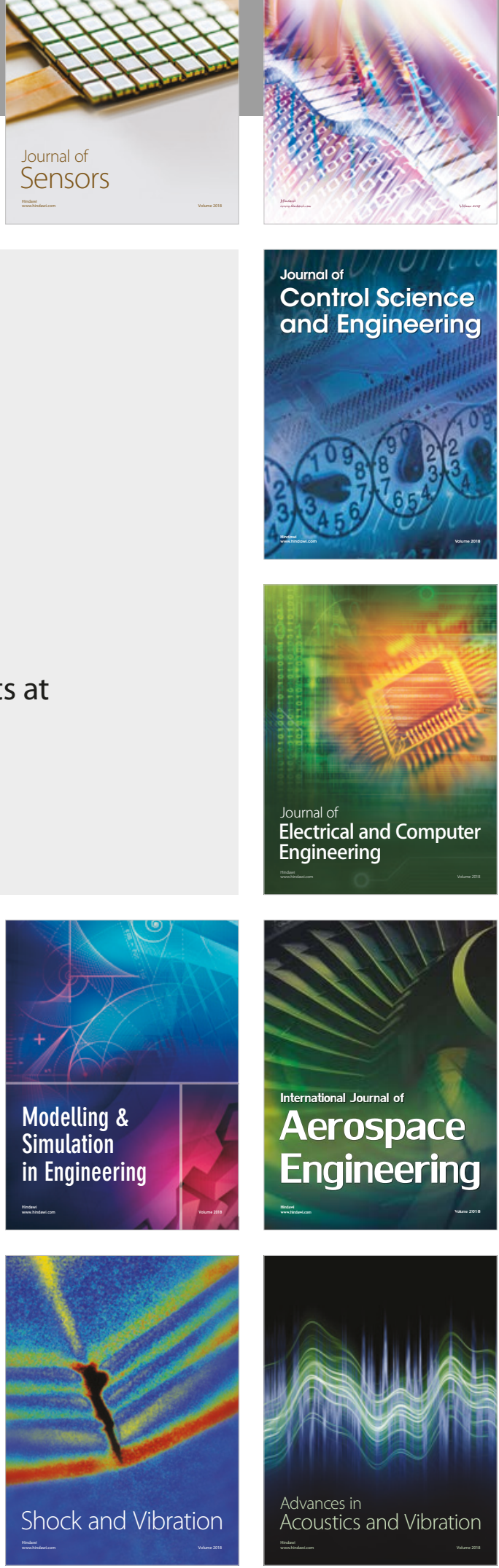